\title{
Neurorestorative Treatment of Stroke: Cell and Pharmacological Approaches
}

\author{
Jieli Chen* and Michael Chopp*广 \\ *Department of Neurology, Henry Ford Health Sciences Center, Detroit, Michigan; and ${ }^{\dagger}$ Department of Physics, Oakland \\ University, Rochester, Michigan
}

\begin{abstract}
Summary: There is a compelling need to develop cell and pharmacological therapeutic approaches to be administered beyond the hyperacute phase of stroke. These therapies capitalize on the capacity of the brain for neuroregeneration and neuroplasticity and are designed to reduce neurological deficits after stroke. This review provides an update of bone marrowderived mesenchymal stem cells (MSCs) and select pharmacological agents in clinical use for other indications that promote the recovery process in the subacute and chronic phases after
\end{abstract}

stroke. Among these agents are 3-hydroxy-3-methylglutarylcoenzyme A reductase inhibitors (statins), erythropoietin (EPO), and phosphodiesterase type 5 (PDE-5) inhibitors and nitric oxide (NO) donors. Both the MSCs and the pharmacologic agents potentiate brain plasticity and neurobehavioral recovery after stroke. Key Words: Stroke, neuronal plasticity, angiogenesis, neurogenesis, synaptogenesis, MSC, pharmacotherapy.

\section{INTRODUCTION}

The time window for effective treatment to enhance stroke recovery is likely to be far longer than that for acute neuroprotective stroke treatments: perhaps days or weeks, rather than minutes or hours after stroke. The extended therapeutic window creates an opportunity to treat most, if not all, stroke patients. Thus, the search for novel cellular and pharmacological therapeutic approaches to be administered beyond the hyperacute phase of ischemia, amplifying the intrinsic properties of the brain for neuroplasticity and subsequent neurological recovery, becomes critical. ${ }^{1}$ Poststroke recovery treatments are likely to enhance structural and functional reorganization (i.e., plasticity) of the damaged brain. This review provides an update of select cellular and pharmacological agents that facilitate neurobehavioral recovery and brain plasticity following stroke.

\section{BIOLOGICAL BASICS OF NEURORESTORATIVE THERAPY}

Neurorestorative events include neurogenesis, angiogenesis, and synaptic plasticity, all of which contribute to

Address correspondence and reprint requests to: Michael Chopp, Ph.D., Neurology Research, E\&R Building, Room 3056, Henry Ford Hospital, 2799 West Grand Boulevard, Detroit, MI 48202. E-mail: chopp@ neuro.hfh.edu. functional improvement after stroke. The adult rodent brain generates neuronal progenitor cells in the subventricular zone (SVZ) and in the dentate gyrus of the hippocampus throughout the life of the animal. The persistence of neurogenesis in the adult mammalian brain suggests that endogenous precursors are a source for neuronal replacement after brain injury. After stroke in the adult brain, the neuroblast population is greatly expanded in the SVZ, and these cells are recruited to areas bordering the infarct, where they can differentiate into neurons and thereby replace lost neurons. ${ }^{2,3}$ In addition, neuroblasts may act synergistically with the microvasculature to stimulate angiogenesis and synaptic activity in the local microenvironment and thereby promote neurological recovery.

Synaptic plasticity is related to behavioral change and functional recovery after brain injury. ${ }^{4}$ Increasing dendritic arborization and spine density are potential morphological strategies for enabling the brain to reorganize its neuronal circuits. ${ }^{5}$ Functional alterations in motor cortex organization are accompanied by changes in dendritic and synaptic structure, as well as by alterations in the regulation of cortical neurotransmitter systems. ${ }^{5,6}$ After a stroke, synaptic activity is increased in the ischemic boundary zone, as evidenced by increased expression of synaptic proteins such as synaptophysin and growthassociated protein 43 . These proteins are amplified with successful neurorestorative treatments. ${ }^{7}$ 
Angiogenesis in the ischemic border creates a hospitable microenvironment for neuronal plasticity, leading to functional recovery. ${ }^{8}$ Greater microvessel density in the ischemic border correlates with longer survival in stroke patients. ${ }^{9}$ Angiogenic vessels express trophic factors (e.g., brain-derived neurotrophic factor, BDNF) and other soluble factors that stimulate recruitment of new neurons and synaptic function. ${ }^{10,11}$ After stroke, neuroblasts are concentrated around blood vessels. ${ }^{12}$ Thus, vascular signaling via angiogenesis influences neuroblast migration and survival. ${ }^{12}$ Neuronal recruitment and angiogenesis are therefore mechanistically linked.

Angiogenesis, neurogenesis, and synaptogenesis comprise an interrelated set of neurorestorative events that facilitate recovery of neurological function. Thus, cellular or pharmacological agents that promote one or more of these restorative events may improve neurological outcome after a stroke. The cellular approach includes a variety of cells, including neural stem and progenitor cells, cord blood, and mesenchymal stem cells (MSCs). ${ }^{13-18}$ The search for pharmacological therapies that potentiate the recovery process after a neurological injury has intensified during the last decade. Many therapeutic agents already marketed have been shown to promote functional outcome after stroke, ${ }^{7,19-22}$ including trophic and growth factors (e.g., vascular endothelial cell growth factor (VEGF), basic fibroblast growth factor (bFGF), and BDNF), granulocyte colony-stimulating factor (G-CSF), angiopoietin 1 (ANG1), angiotensin modulators, minocycline, and thiazolidinediones. In addition, various agents with widespread application for other medical indications have neurorestorative effects on injured cerebral tissue. Among these are statins, erythropoietin (EPO), and phosphodiesterase type 5 (PDE-5) inhibitors.

We now review the use of select cellular and pharmacological agents, all of which stimulate neurogenesis, angiogenesis, and synaptogenesis and appear to possess neurorestorative properties. The eventual movement of these agents into clinical use will depend on the rigorous demonstration of efficacy in preclinical models of stroke, clinical safety, and realistic dosing protocols. Here, we focus on a particular cell-based therapy, MSC, and on three categories of neurorestorative agents: (1) the 3-hydroxy-3-methylglutaryl-coenzyme A reductase inhibitors (statins); (2) EPO; and (3) PDE-5 inhibitors. This is by no means an exhaustive list, but simply represents classes of cellular or neurorestorative agents, some of which are likely candidates for clinical use. A common thread in the neurorestorative therapies is that they increase parenchymal cell expression of VEGF and angiogenesis.

\section{MSC TREATMENT OF STROKE}

\section{MSC neurorestorative therapy}

The regenerative potential of MSCs has been demonstrated in myocardial, limb, and brain ischemia. ${ }^{23}$ MSC administration starting 24 hours after stroke promotes functional outcome after stroke, whether by intracerebral, intravenous, or intra-arterial route. ${ }^{17,18}$ In addition, delayed treatment of stroke with MSCs at 7 days or at 1 month after stroke onset also increases brain plasticity and improves long-term functional outcome. ${ }^{17,24,25}$

\section{Mechanisms of MSC neurorestorative effect}

MSCs are multipotential, and can differentiate into various tissue lineages, including astrocytes, neurons, and endothelial cells in the brain. ${ }^{18,26}$ When MSCs are administered 24 hours after stroke, functional outcome is significantly improved from 7 days after treatment. ${ }^{27}$ This benefit is probably not attributable to the very few MSCs that differentiate into brain cells. Instead, the active principle seems to be that MSCs secrete various growth factors (e.g., VEGF, bFGF, and BDNF) that promote functional outcome after stroke, ${ }^{28-32}$ thus amplifying their endogenous brain levels. These growth factors support and amplify angiogenesis, neurogenesis, and synaptic plasticity. ${ }^{33,34}$ MSCs thus behave as small biochemical and molecular factories and catalysts, producing and inducing within parenchymal cells many cytokines and trophic factors that enhance angiogenesis and vascular stabilization in the ischemic boundary (which is where the majority of MSCs that survive in the brain are located). ${ }^{35}$

In addition, neurogenesis in the SVZ and synaptogenesis are greatly amplified by MSC treatment. MSCs also induce other agents within injured brain, such as bone morphogenetic proteins BMP2 and BMP4 or connexin 43 expression in astrocytes. ${ }^{36}$ In concert with enhancing angiogenesis, neurogenesis, and synaptogenesis, MSCs significantly decrease glial scar formation and promote glial-axonal remodeling. ${ }^{24}$ Thus, MSCs act in a pleiotropic way to stimulate brain remodeling.

Basic and clinical data support the translation of MSC therapy to clinical trials. Stroke patients treated with autologous MSCs (i.v.) show improved functional recovery after stroke. ${ }^{37}$ The procedures of ex vivo expansion of autologous MSCs and of transplantation are safe and well tolerated. ${ }^{37,38}$ MSCs are not immunorejective, and allogeneic cells can be used. ${ }^{39,40}$ Thus, MSC treatment is poised for clinical trials in stroke. Preclinical data point to other cell therapies that appear highly efficacious in reducing neurological deficits after stroke, ${ }^{15,22,41}$ and we expect that these cells will also enter the clinical arena.

A major benefit of cell-based therapy is that cells administered via a vascular route distribute themselves throughout the entire region of compromised tissue. They serve as a distributed network of polypharmacy and a catalysis for neurorestoration. Benefit derives essentially from stimulating and amplifying the endogenous restorative mechanisms residing in brain. It is likely that feedback loops sensitive to the microenvironment of the 
compromised tissue titrate the restorative response to exogenous cells to safe and effective levels.

\section{PHARMACOLOGICAL TREATMENT OF STROKE}

\section{Statins}

Statins are potent inhibitors of cholesterol biosynthesis and also benefit stroke. The mechanism by which statins provide benefit against stroke is likely multifactorial, involving reduction of low-density lipoprotein cholesterol along with stabilization of vulnerable plaques. Statins also render cortical neurons more resistant to NMDA-induced excitotoxic death. Many of the pleiotropic effects of statins are cholesterol independent, such as improvement of endothelial function, increased NO bioavailability, antioxidant properties, inhibition of inflammatory responses, immunomodulatory actions, upregulation of endothelial nitric oxide synthase (eNOS), decrease of platelet activation, and regulation of progenitor cells. ${ }^{42,43}$ Pretreatment of stroke with statins reduces brain infarct size and improves neurological outcome by directly upregulating brain eNOS. ${ }^{44,45}$ Combination atorvastatin and recombinant human tissue plasminogen activator (rhtPA) treatment 4 hours after stroke induces downregulation of tissue factor, protease-activated receptor 1 , intercellular adhesion molecule 1 , and matrix metalloproteinase 9 (MMP 9); concomitantly, it reduces cerebral microvascular thrombosis and enhances microvascular integrity. ${ }^{46}$ Patients who had taken statins prior to the onset of stroke have significantly decreased mortality and improved outcome after acute ischemic stroke. ${ }^{47,48}$ The results of the recently reported in stroke prevention by aggressive reduction in cholesterol levels (SPARCL) trial indicate that atorvastatin is likely efficacious in reducing the incidence of recurring stroke. ${ }^{119}$

Neurorestorative effects of statins. Low-dose statin administered 24 hours after stroke promotes angiogenesis, neurogenesis, and synaptic plasticity and improves neurological functional outcome after stroke in young and in older retired breeder rats (middle age). ${ }^{49,50}$ Treatment of patients within 4 weeks after acute ischemic stroke with statins significantly increased favorable outcome at 12 weeks. ${ }^{51}$ In addition, the efficacy, safety, and tolerability of statins have been confirmed in randomized, controlled, multicenter trials involving large numbers of patients aged $\geq 65$ years. ${ }^{52}$ Elderly patients taking lipid-lowering agents, such as statins, at the time of an ischemic stroke have lower poststroke mortality and a lower risk of worsening during hospitalization. ${ }^{48}$

\section{Mechanisms of statin-induced neurorestoration.} Molecular mechanisms underlying the role of statins in the induction of brain plasticity and subsequent improvement of neurological outcome after treatment of stroke include the statin-mediated increase of eNOS, VEGF-
VEGFR2, BDNF, tPA, phosphatidylinositol 3'-kinase (PI3K)-AKT, and small $\mathrm{G}$ proteins in the ischemic brain. ${ }^{53}$ These proteins play an important role in regulating vascular and neurogenic, neuroprotective, and neurorestorative effects. ${ }^{54,55}$

Specific cell populations and neurorestorative processes are targeted by statins. Statins increase brain endothelial cell expression of VEGF-VEGFR2 and eNOS and thereby activate the PI3K-AKT pathway, which regulates endothelial cell proliferation and migration and increases angiogenesis. ${ }^{56}$ Statins also increase vascular stabilization and decrease blood-brain barrier (BBB) permeability after stroke. ${ }^{57}$ The effect of statins on the induction of angiogenesis, however, is dose dependent and biphasic. ${ }^{58}$ Some authors particularly highlight the proangiogenic effects of statins caused by low, nanomolar concentrations and regarded as beneficial for the treatment of vascular diseases. ${ }^{58}$ Others have found that a high dose of statins promotes endothelial cell death and inhibits experimental angiogenesis induced by growth factors or tumor, laying a foundation for developing statin-based angiopreventive strategies. ${ }^{59}$

In addition to their effects on cerebrovascular function, statins increase neurogenesis in ischemic brain, protect cortical neurons from excitotoxicity, and increase neurite outgrowth and synaptic plasticity. ${ }^{50,53,60,61}$ Atorvastatin treatment after stroke induces endogenous SVZ progenitor cell proliferation and migration to the ischemic border and neuronal differentiation. ${ }^{50,53}$ Statins increase the expression of BDNF and synaptic proteins and also increase neuroblast migration to blood vessels. ${ }^{53}$

Neurogenesis and synaptic reorganization are important for functional improvement after stroke. Neurogenesis declines with advancing age. Thus, repairing the aged ischemic brain and promoting functional outcome may be significantly more challenging than in the young brain. Several signaling cascades play important roles in the regulation of statin-induced neurogenesis. Transcription factors with basic helix-loop-helix (bHLH) motifs are essential elements in neurogenesis. The Mash1 protein encodes a bHLH transcription factor, which controls the correct timing of differentiation during neuronal development. ${ }^{62}$ Atorvastatin increased Mash1 gene and protein expression in the ischemic brain, and promoted neuronal differentiation in retired breeder rats. ${ }^{49}$ Thus, the molecular mechanisms by which statins alter vascular and neurogenic status in young and older brains are becoming more clear.

Given the wide use of statins, their favorable safety profile in patients, the extensive preclinical data showing both neuroprotection and neurorestoration, and provocative positive clinical data in stroke patients, clinical studies are warranted to determine neuroprotective and neurorestorative properties of statins after stroke. 


\section{Erythropoietin}

EPO as a neurorestorative agent. EPO is a hematopoietic growth hormone that regulates survival, proliferation, and differentiation of erythroid progenitor cells. EPO is widely used in the treatment of anemia in cancer patients undergoing chemotherapy. EPO and EPO receptor (EPOR) are weakly expressed in normal adult brain, but they are dramatically upregulated in response to brain hypoxia and metabolic distress of neurons. ${ }^{63}$

EPOR is important for adult neurogenesis and for migration of regenerating neurons during postinjury recovery. ${ }^{64} \mathrm{EPO}$ can pass the $\mathrm{BBB},{ }^{55}$ and is well tolerated and safe in the stroke patient. ${ }^{65,66}$ In preclinical studies, treatment with EPO at 24 hours after onset of stroke significantly improved functional outcome. ${ }^{67} \mathrm{EPO}$ treatment in rodent initiated 1 day after experimental traumatic brain injury is neurorestorative (by enhancing neurogenesis) and neuroprotective, and it significantly improves spatial memory function. ${ }^{68}$ EPO inhibits axonal degeneration and therefore may be therapeutically useful in a wide variety of human neurological diseases characterized by axonopathy. ${ }^{69}$

In clinical studies, stroke patients receiving recombinant human EPO (rHuEPO) within 5 hours of the onset of cerebral ischemic symptoms showed a significantly improved clinical progress, as well as a reduced infarct size as measured by MRI, compared with placebo-treated patients. ${ }^{65}$ The Gottingen EPO Stroke Study, a multicenter pilot study for proof of concept (preceding the necessary phase III trial), is ongoing in Germany. ${ }^{65,70}$ EPO is the first compound with a favorable safety profile to show significant beneficial effects in stroke patients. Although the use of rHuEPO is not without side-effects (e.g., hypertension, thrombosis, and increased hematocrit), the clinical benefits of rHuEPO in other applications cannot be ignored. Recently introduced, carbamylated erythropoietin (CEPO) does not stimulate erythropoiesis but retains the antiapoptotic and neuroprotective effects of EPO. ${ }^{71,72}$ Treatment with CEPO 24 hours after stroke reduces perifocal microglial activation and white matter damage, and significantly improves functional outcome after stroke. ${ }^{73}$

Mechanisms of EPO-induced neurorestoration. EPO is a pleiotropic cytokine that is proangiogenic. ${ }^{74} \mathrm{EPO}$ and EPOR are expressed in the vasculature during embryogenesis. EPO regulates endothelial cell proliferation and migration and it increases angiogenesis, erythropoiesis, and vascular resistance. ${ }^{75}$ EPO also engages diverse cellular pathways, such as those involving Janus kinase 2 (JAK2), signal transducers and activators of transcription (STATs), mitogen-activated protein kinases (MAPKs), Bcl- $\mathrm{x}_{\mathrm{L}}$, protein kinase $\mathrm{B}$, protein kinase $\mathrm{C}$, and cysteine proteases to provide plasticity to vascular systems through highly conserved mechanisms. ${ }^{76}$ Moreover, EPO upregulates ANG1 expression under normoxic conditions ${ }^{77}$ and protects the in vitro BBB against VEGF-induced permeability. ${ }^{78}$

Treatment of stroke rats with EPO increases angiogenesis in the ischemic border. ${ }^{67} \mathrm{EPO}$ promotes endothelial cell secretion of MMP 2 and MMP 9, which are chemotactic for neuroblast migration. ${ }^{79}$ VEGF and BDNF expression in the ischemic brain are increased in response to EPO, and may provide a vascular niche, a microenvironment supporting migrating neuroblasts. EPO infusion into the adult lateral ventricles increases the number of newly generated cells migrating to the olfactory bulb, and thereby increases new olfactory bulb interneurons. ${ }^{80}$ The JAK2-STAT3 and PI3K-AKT pathways activated by EPO may also underlie the EPO-mediated neuronal regeneration. ${ }^{81}$ Thus, multiple signaling pathways may regulate the EPO-induced angiogenesis and neurogenesis that promote neurorestorative effects after stroke.

\section{PDE-5 inhibitors, cGMP, and NO donors}

cGMP is a molecular messenger involved in diverse cellular processes, including regulation of cellular proliferation. ${ }^{82}$ Increases in cGMP levels enhance proliferation of endothelial cells and motor neurons. ${ }^{83}$ Thus, increased cGMP production may facilitate neuroprotection and neurorestoration after stroke. cGMP levels in brain may be increased by cGMP production via increases in NO or inhibition of cGMP hydrolysis. NO activates soluble guanylyl cyclase and leads to the formation of cGMP in target cells. PDE-5 inhibitors are a new class of vasoactive drugs (including sildenafil, vardenafil, zaprinast, and tadalafil) developed for treatment of erectile dysfunction in patients. ${ }^{84}$ These drugs competitively inhibit cGMP hydrolysis by PDE-5, thereby fostering cGMP accumulation and relaxation of vascular smooth muscle. ${ }^{85}$ Sildenafil significantly increases cerebral cGMP. ${ }^{86,87}$

Neurorestorative effect of PDE-5 inhibitors. Chronic treatment of stroke-prone, spontaneously hypertensive rats with DA-8159, a new PDE-5 inhibitor, increases cerebral blood flow in the ischemic brain, plasma NO, cGMP, and the total antioxidative status and attenuates endothelial dysfunction. ${ }^{88}$ Treatment of stroke with sildenafil starting at 24 hours after stroke significantly increased brain levels of cGMP, evoked neurogenesis, and reduced neurological deficits after stroke in both young adult and aged rats. ${ }^{86,89}$ Increasing age decreases the number of new neurons in the dentate gyrus and the SVZ. ${ }^{90}$ Sildenafil not only enhances angiogenesis and neurogenesis in young adults, but also augments angiogenesis and neurogenesis in aged ischemic rats. ${ }^{91}$

Molecular mechanisms underlying functional benefit include a sildenafil-mediated increase in phosphorylated AKT, which increases phosphorylation of glycogen synthase kinase $3 .^{92}$ Sildenafil also attenuates learning impairment induced by blockade of cholinergic muscarinic receptors in rats by modulating NO-cGMP signal transduction, a 
pathway implicated in age-related cognitive decline and neurodegenerative disease. ${ }^{93}$ Therefore, in addition to promoting neuroregeneration after stroke treatment, sildenafil may also enhance cognitive function, and can be used to treat cholinergic dysfunction in age-related cognitive decline and Alzheimer's dementia (AD).

Neurorestorative effect of NO donors. NO donors produce neurorestorative effects after stroke both by increasing cGMP and through other complementary pathways. In the CNS, NO is an important physiological messenger involved in the modulation of brain development, synaptic plasticity, neuroendocrine secretion, sensory processing, and cerebral blood flow. ${ }^{94}$

Cerebrovascular protection by various NO donors after experimental stroke has been reported in rat. ${ }^{95} \mathrm{NO}$ promotes angiogenesis and neurogenesis, and increases neuroblast migration. Stroke rats exhibit significant improvements of neurological outcome during recovery from ischemic stroke when administration of DETA-NONOate to rats is initiated at 24 hours after stroke. ${ }^{96,97} \mathrm{NO}$ has a prominent role in the regulation of cerebral blood flow and the modulation of cell-to-cell communication in the brain. ${ }^{98}$ L-arginine increases cerebral blood perfusion and improves vasomotion of microvessels by enhancing NO levels. ${ }^{99}$ Systemic administration of a low dose of the NO donor DETA-NONOate to rats 24 hours after stroke significantly induced angiogenesis in the ischemic boundary regions. ${ }^{96}$

NO donors such as SNAP, GSNO, and NOC also regulate HIF-1-mediated VEGF gene activation and promote angiogenesis. ${ }^{100}$ In addition, NO upregulates expression of $\alpha_{\mathrm{v}} \beta_{3}$ integrin (a critical mediator of cellmatrix adhesion and cell migration) on endothelial cells and promotes angiogenesis. ${ }^{101} \mathrm{NO}$ also increases vascular stabilization ${ }^{96,100}$ via upregulation of the ANG1-Tie2 pathway ${ }^{102}$ and mediates mural cell recruitment and vessel morphogenesis in murine melanomas and tissue-engineered blood vessels. ${ }^{103}$

NO regulates neurogenesis in the adult brain. ${ }^{97}$ DETANONOate promotes neuronal differentiation and neurite outgrowth in both young and older SVZ neurospheres. ${ }^{104}$ DETA-NONOate modulation of SVZ cell differentiation is controlled by $\mathrm{N}$-cadherin, $\beta$-catenin, and neurogenin 1 gene expression. ${ }^{104}$ The NO-cGMP-protein kinase G (PKG) signaling pathway facilitates communication between neurons and glia, ${ }^{105}$ and enhances neurotrophin-induced neurite outgrowth. ${ }^{106}$ As described above, EPO and EPOR promote adult neurogenesis and migration of regenerating neurons during postinjury recovery. ${ }^{64} \mathrm{NO}$ modulates hypoxic stimulation of EPO production ${ }^{107}$ and L-arginine rescues decreased EPO gene expression by stimulating GATA-2 with NG-monomethyl-L-arginine. ${ }^{108}$ Therefore, NO upregulation of EPO production may also play an important role in promoting brain plasticity. Thus, agents that chronically increase NO in brain appear to be neurorestorative and may be candidates for clinical development.

\section{VASCULAR ENDOTHELIAL GROWTH FACTOR}

VEGF is a trophic factor common to both cell and pharmacological neurorestorative therapy.

Administration of MSCs and agents such as statins, EPO, or PDE-5 inhibitors (e.g., sildenafil and tadalafil) and NO donors (e.g., DETA-NONOate) after stroke all significantly increase ischemic brain VEGF expression and promote functional recovery without affecting lesion volume. ${ }^{53,67,86,96,97}$ Thus, induction of VEGF is likely a major contributor to neurorecovery after stroke. Direct administration of VEGF or indirect upregulation of VEGF in ischemic brain by cell or pharmacological means may promote functional recovery after stroke.

VEGF is an angiogenic protein with a wide variety of physiological and molecular effects; it has therapeutic potential in ischemic disorders, including stroke. VEGF increases endothelial cell proliferation, migration, and angiogenesis after stroke; it also modulates the PI3KAKT-nuclear factor kappa B signaling pathway, inhibits caspase-3 activity, and reduces ischemic neuronal apoptosis. ${ }^{109,110}$ However, early postischemic (1 hour) administration of recombinant human VEGF165 (rhVEGF165) to ischemic rats increased BBB leakage and infarction volume in the ischemic brain. ${ }^{111}$ In contrast, late (48 hours) administration of rhVEGF165 to ischemic rats enhanced angiogenesis in the ischemic penumbra and significantly improved neurological recovery, ${ }^{111}$ and combination ANG1-VEGF treatment decreased BBB leakage and promoted angiogenesis. ${ }^{112}$

VEGF stimulates angiogenesis and neurogenesis, and improves functional outcome after stroke, through multiple mechanisms. ${ }^{113,114}$ Among other effects, VEGF is a chemoattractant for bFGF-stimulated neural progenitors. ${ }^{115}$ VEGF increases ischemia-induced tyrosine phosphorylation of Kv1.2 potassium channel proteins via activation of the PI3K pathway, enhances proliferation and migration of neural progenitors in the SVZ, and improves striatal neurogenesis, neuronal differentiation, and maturation of neuroblasts in adult rat brains after stroke. ${ }^{109,116,117}$

VEGF can be induced in ischemic brain by both cellbased and pharmacological restoration therapies. In most preclinical and clinical studies, however, the introduction of these factors as single agents has resulted in the formation of stabilized blood vessels of only limited duration. ${ }^{118}$ Drawbacks of administering VEGF directly include the potential adverse effects of inducing hemorrhage. To our knowledge, no clinical trials are planned or proposed to treat stroke using VEGF. A more reasonable approach to capitalizing on the potential benefit of VEGF is through pharmacological agents that stimulate endogenous production of VEGF. 


\section{CONCLUSION}

Here we have partially summarized the use of MSCs and pharmacological agents in clinical use that have potential to improve neurological function when administered, after stroke, or later. All of these agents increase VEGF levels and activate signal transduction pathways that remodel brain by inducing neurogenesis, angiogenesis, synaptic plasticity, and structural changes that augment functional improvement after a stroke. MSCs and many of these therapeutic molecules have long and safe medical histories from their use in treatment of other medical conditions. The literature reviewed here shows that the injured brain can be stimulated to improve neurological function. Many of these restorative events, such as angiogenesis, neurogenesis, and synaptic plasticity occur naturally after stroke, but they can also be amplified by cell and pharmacological interventions to restore neurological function after a cerebral insult.

Acknowledgments: This work was supported by NINDS grants P01 NS23393, R01 NS047682.

\section{REFERENCES}

1. Gladstone DJ, Black SE, Hakim AM; Heart and Stroke Foundation of Ontario Centre of Excellence in Stroke Recovery. Toward wisdom from failure: lessons from neuroprotective stroke trials and new therapeutic directions. Stroke 2002;33:2123-2136.

2. Parent JM, Vexler ZS, Gong C, Derugin N, Ferriero DM. Rat forebrain neurogenesis and striatal neuron replacement after focal stroke. Ann Neurol 2002;52:802-813.

3. Arvidsson A, Collin T, Kirik D, Kokaia Z, Lindvall O. Neuronal replacement from endogenous precursors in the adult brain after stroke. Nat Med 2002;8:963-970.

4. Nudo RJ. Functional and structural plasticity in motor cortex: implications for stroke recovery. Phys Med Rehabil Clin N Am 2003; 14:S57-S76.

5. Nudo RJ, Plautz EJ, Frost SB. Role of adaptive plasticity in recovery of function after damage to motor cortex. Muscle Nerve 2001;24:1000-1019.

6. Bohotin CR, Badescu M, Popescu DN, Bohotin V. Motor cortex plasticity: from physiology to clinical neurology. Rom J Physiol 2004;41:99-108.

7. Stroemer RP, Kent TA, Hulsebosch CE. Enhanced neocortical neural sprouting, synaptogenesis, and behavioral recovery with D-amphetamine therapy after neocortical infarction in rats. Stroke 1998;29:2381-2393; discussion 2393-2395.

8. Plate KH. Mechanisms of angiogenesis in the brain. J Neuropathol Exp Neurol 1999;58:313-320.

9. Krupinski J, Kaluza J, Kumar P, Kumar S, Wang JM. Role of angiogenesis in patients with cerebral ischemic stroke. Stroke 1994;25:1794-1798.

10. Leventhal C, Rafii S, Rafii D, Shahar A, Goldman SA. Endothelial trophic support of neuronal production and recruitment from the adult mammalian subependyma. Mol Cell Neurosci 1999;13: 450-464.

11. Bibel M, Barde YA. Neurotrophins: key regulators of cell fate and cell shape in the vertebrate nervous system. Genes Dev 2000;14:2919-2937.

12. Louissaint A Jr, Rao S, Leventhal C, Goldman SA. Coordinated interaction of neurogenesis and angiogenesis in the adult songbird brain. Neuron 2002;34:945-960.

13. Kim DE, Schellingerhout D, Ishii K, Shah K, Weissleder R. Imaging of stem cell recruitment to ischemic infarcts in a murine model. Stroke 2004;35:952-957.
14. Newman MB, Willing AE, Manresa JJ, Davis-Sanberg C, Sanberg PR. Stroke-induced migration of human umbilical cord blood cells: time course and cytokines. Stem Cells Dev 2005;14:576-586.

15. Newcomb JD, Ajmo CT Jr, Sanberg CD, Sanberg PR, Pennypacker KR, Willing AE. Timing of cord blood treatment after experimental stroke determines therapeutic efficacy. Cell Transplant 2006;15:213-223.

16. Auerbach JM, Eiden MV, McKay RD. Transplanted CNS stem cells form functional synapses in vivo. Eur J Neurosci 2000;12: 1696-1704.

17. Chen J, Li Y, Wang L, et al. Therapeutic benefit of intravenous administration of bone marrow stromal cells after cerebral ischemia in rats. Stroke 2001;32:1005-1011.

18. Zhao LR, Duan WM, Reyes M, Keene CD, Verfaillie CM, Low WC. Human bone marrow stem cells exhibit neural phenotypes and ameliorate neurological deficits after grafting into the ischemic brain of rats. Exp Neurol 2002;174:11-20.

19. Fagan SC, Hess DC, Machado LS, Hohnadel EJ, Pollock DM, Ergul A. Tactics for vascular protection after acute ischemic stroke. Pharmacotherapy 2005;25:387-395.

20. Dahlqvist P, Ronnback A, Risedal A, et al. Effects of postischemic environment on transcription factor and serotonin receptor expression after permanent focal cortical ischemia in rats. Neuroscience 2003;119:643-652.

21. Jin K, Sun Y, Xie L, Childs J, Mao XO, Greenberg DA. Postischemic administration of heparin-binding epidermal growth factor-like growth factor (HB-EGF) reduces infarct size and modifies neurogenesis after focal cerebral ischemia in the rat. J Cereb Blood Flow Metab 2004;24:399-408.

22. Jin K, Sun Y, Xie L, et al. Comparison of ischemia-directed migration of neural precursor cells after intrastriatal, intraventricular, or intravenous transplantation in the rat. Neurobiol Dis 2005; 18:366-374.

23. Dezawa M, Hoshino M, Nabeshima Y, Ide C. Marrow stromal cells: implications in health and disease in the nervous system. Curr Mol Med 2005;5:723-732.

24. Li Y, Chen J, Zhang CL, et al. Gliosis and brain remodeling after treatment of stroke in rats with marrow stromal cells. GLIA 2005;49:407-417.

25. Shen LH, Li Y, Chen J, et al. Therapeutic benefit of bone marrow stromal cells administered 1 month after stroke. J Cereb Blood Flow Metab 2006. Epub 2006 Apr 5. doi: 10.1038/ sj.jcbfm.9600311.

26. Wislet-Gendebien S, Bruyere F, Hans G, Leprince P, Moonen G, Rogister B. Nestin-positive mesenchymal stem cells favour the astroglial lineage in neural progenitors and stem cells by releasing active BMP4. BMC Neurosci 2004;5:33.

27. Li Y, Chen J, Chen XG, et al. Human marrow stromal cell therapy for stroke in rat: neurotrophins and functional recovery. Neurology 2002;59:514-523.

28. Chen X, Li Y, Wang L, et al. Ischemic rat brain extracts induce human marrow stromal cell growth factor production. Neuropathology 2002;22:275-279.

29. Zhao MZ, Nonoguchi N, Ikeda N, et al. Novel therapeutic strategy for stroke in rats by bone marrow stromal cells and ex vivo HGF gene transfer with HSV-1 vector. J Cereb Blood Flow Metab 2006. Epub 2006 Jan 18.

30. Hanabusa K, Nagaya N, Iwase T, et al. Adrenomedullin enhances therapeutic potency of mesenchymal stem cells after experimental stroke in rats. Stroke 2005;36:853-838.

31. Kurozumi K, Nakamura K, Tamiya T, et al. Mesenchymal stem cells that produce neurotrophic factors reduce ischemic damage in the rat middle cerebral artery occlusion model. Mol Ther 2005;11:96-104.

32. Ikeda N, Nonoguchi N, Zhao MZ, Watanabe T, Kajimoto Y, Furutama D, Kimura F, Dezawa M, Coffin RS, Otsuki Y, Kuroiwa T, Miyatake $\mathrm{S}$. Bone marrow stromal cells that enhanced fibroblast growth factor-2 secretion by herpes simplex virus vector improve neurological outcome after transient focal cerebral ischemia in rats. Stroke 2005;36:2725-2730.

33. Carmeliet P, Storkebaum E. Vascular and neuronal effects of VEGF in the nervous system: implications for neurological disorders. Semin Cell Dev Biol 2002;13:39-53.

34. Jin K, Zhu Y, Sun Y, Mao XO, Xie L, Greenberg DA. Vascular 
endothelial growth factor (VEGF) stimulates neurogenesis in vitro and in vivo. Proc Natl Acad Sci U S A 2002;99:11946-11950.

35. Chen J, Zhang ZG, Li Y, et al. Intravenous administration of human bone marrow stromal cells induces angiogenesis in the ischemic boundary zone after stroke in rats. Circ Res 2003;92: 692-699.

36. Zhang C, Li Y, Chen J, Gao Q, Zacharek A, Kapke A, et al. Bone marrow stromal cells upregulate expression of bone morphogenetic proteins 2 and 4, gap junction protein connexin-43 and synaptophysin after stroke in rats. Neuroscience 2006;141:687695.

37. Bang OY, Lee JS, Lee PH, Lee G. Autologous mesenchymal stem cell transplantation in stroke patients. Ann Neurol 2005;57:874882.

38. Mazzini L, Fagioli F, Boccaletti R, et al. Stem cell therapy in amyotrophic lateral sclerosis: a methodological approach in humans. Amyotroph Lateral Scler Other Motor Neuron Disord 2003;4:158-161.

39. Pittenger MF, Martin BJ. Mesenchymal stem cells and their potential as cardiac therapeutics. Circ Res 2004;95:9-20.

40. Aggarwal S, Pittenger MF. Human mesenchymal stem cells modulate allogeneic immune cell responses. Blood 2005;105:18151822.

41. Savitz SI, Dinsmore JH, Wechsler LR, Rosenbaum DM, Caplan LR. Cell therapy for stroke. NeuroRx 2004;1:406-414.

42. Walter DH, Rittig K, Bahlmann FH, et al. Statin therapy accelerates reendothelialization: a novel effect involving mobilization and incorporation of bone marrow-derived endothelial progenitor cells. Circulation 2002;105:3017-3024.

43. Liao JK. Clinical implications for statin pleiotropy. Curr Opin Lipidol 2005;16:624-629.

44. Endres M, Laufs U, Huang Z, et al. Stroke protection by 3-hydroxy-3-methylglutaryl (HMG)-CoA reductase inhibitors mediated by endothelial nitric oxide synthase. Proc Natl Acad Sci U S A 1998:95:8880-8885.

45. Laufs U, Gertz K, Dirnagl U, Bohm M, Nickenig G, Endres M. Rosuvastatin, a new HMG-CoA reductase inhibitor, upregulates endothelial nitric oxide synthase and protects from ischemic stroke in mice. Brain Res 2002;942:23-30.

46. Zhang L, Zhang ZG, Ding GL, et al. Multitargeted effects of statin-enhanced thrombolytic therapy for stroke with recombinant human tissue-type plasminogen activator in the rat. Circulation 2005;112:3486-3494.

47. Aslanyan S, Weir CJ, McInnes GT, Reid JL, Walters MR, Lees KR. Statin administration prior to ischaemic stroke onset and survival: exploratory evidence from matched treatment-control study. Eur J Neurol 2005;12:493-498.

48. Elkind MS, Flint AC, Sciacca RR, Sacco RL. Lipid-lowering agent use at ischemic stroke onset is associated with decreased mortality. Neurology 2005;65:253-258.

49. Chen J, Zacharek A, Li A, et al. Vascular endothelial growth factor mediates atorvastatin-induced mammalian achaete-scute homologue-1 gene expression and neuronal differentiation after stroke in retired breeder rats. Neuroscience 2006;141:737-744.

50. Chen J, Zhang ZG, Li Y, et al. Statins induce angiogenesis, neurogenesis, and synaptogenesis after stroke. Ann Neurol 2003; 53:743-751.

51. Moonis M, Kane K, Schwiderski U, Sandage BW, Fisher M. HMG-CoA reductase inhibitors improve acute ischemic stroke outcome. Stroke 2005;36:1298-1300.

52. Jacobson TA. Overcoming 'ageism' bias in the treatment of hypercholesterolaemia: a review of safety issues with statins in the elderly. Drug Saf 2006;29:421-448.

53. Chen J, Zhang C, Jiang $\mathrm{H}$, et al. Atorvastatin induction of VEGF and BDNF promotes brain plasticity after stroke in mice. J Cereb Blood Flow Metab 2005;25:281-290.

54. Dimmeler S, Aicher A, Vasa M, et al. HMG-CoA reductase inhibitors (statins) increase endothelial progenitor cells via the PI 3-kinase/Akt pathway. J Clin Invest 2001;108:391-397.

55. Maeda T, Kawane T, Horiuchi N. Statins augment vascular endothelial growth factor expression in osteoblastic cells via inhibition of protein prenylation. Endocrinology 2003;144:681-692.
56. Walter DH, Zeiher AM, Dimmeler S. Effects of statins on endothelium and their contribution to neovascularization by mobilization of endothelial progenitor cells. Coron Artery Dis 2004;15: $235-242$.

57. Mooradian AD, Haas MJ, Batejko O, Hovsepyan M, Feman SS. Statins ameliorate endothelial barrier permeability changes in the cerebral tissue of streptozotocin-induced diabetic rats. Diabetes 2005;54:2977-2982.

58. Frick M, Dulak J, Cisowski J, et al. Statins differentially regulate vascular endothelial growth factor synthesis in endothelial and vascular smooth muscle cells. Atherosclerosis 2003;170:229-236.

59. Dulak J, Jozkowicz A. Anti-angiogenic and anti-inflammatory effects of statins: relevance to anti-cancer therapy. Curr Cancer Drug Targets 2005;5:579-594.

60. Pooler AM, Xi SC, Wurtman RJ. The 3-hydroxy-3-methylglutaryl co-enzyme A reductase inhibitor pravastatin enhances neurite outgrowth in hippocampal neurons. J Neurochem 2006;97: 716-723.

61. Zacco A, Togo J, Spence K, Ellis A, Lloyd D, Furlong S, Piser T. 3-hydroxy-3-methylglutaryl coenzyme A reductase inhibitors protect cortical neurons from excitotoxicity. J Neurosci 2003;23: $11104-11111$.

62. Horton S, Meredith A, Richardson JA, Johnson JE. Correct coordination of neuronal differentiation events in ventral forebrain requires the bHLH factor MASH1. Mol Cell Neurosci 1999;14: 355-369.

63. Bernaudin M, Marti HH, Roussel S, et al. A potential role for erythropoietin in focal permanent cerebral ischemia in mice. J Cereb Blood Flow Metab 1999;19:643-651.

64. Tsai PT, Ohab JJ, Kertesz N, et al. A critical role of erythropoietin receptor in neurogenesis and post-stroke recovery. J Neurosci 2006;26:1269-1274.

65. Ehrenreich H, Hasselblatt M, Dembowski C, et al. Erythropoietin therapy for acute stroke is both safe and beneficial. Mol Med 2002;8:495-505.

66. Brines ML, Ghezzi P, Keenan S, Agnello D, de Lanerolle NC, Cerami C, Itri LM, Cerami A. Erythropoietin crosses the bloodbrain barrier to protect against experimental brain injury. Proc Natl Acad Sci U S A 2000;97:10526-10531.

67. Wang L, Zhang Z, Wang Y, Zhang R, Chopp M. Treatment of stroke with erythropoietin enhances neurogenesis and angiogenesis and improves neurological function in rats. Stroke 2004;35: 1732-1737.

68. Lu D, Mahmood A, Qu C, Goussev A, Schallert T, Chopp M. Erythropoietin enhances neurogenesis and restores spatial memory in rats after traumatic brain injury. J Neurotrauma 2005;22: 1011-1017.

69. Keswani SC, Buldanlioglu U, Fischer A, et al. A novel endogenous erythropoietin mediated pathway prevents axonal degeneration. Ann Neurol 2004;56:815-826.

70. Ehrenreich H, Timner W, Siren AL. A novel role for an established player: anemia drug erythropoietin for the treatment of cerebral hypoxia/ischemia. Transfus Apher Sci 2004;31: 39-44.

71. Leist M, Ghezzi P, Grasso G, et al. Derivatives of erythropoietin that are tissue protective but not erythropoietic. Science 2004; 305:239-242.

72. Moon C, Krawczyk M, Paik D, et al. Erythropoietin, modified to not stimulate red blood cell production, retains its cardioprotective properties. J Pharmacol Exp Ther 2006;316:999-1005.

73. Villa P, van Beek J, Larsen AK, et al. Reduced functional deficits, neuroinflammation, and secondary tissue damage after treatment of stroke by nonerythropoietic erythropoietin derivatives. J Cereb Blood Flow Metab 2006. Epub 2006 Jul 12.

74. Hardee ME, Arcasoy MO, Blackwell KL, Kirkpatrick JP, Dewhirst MW. Erythropoietin biology in cancer. Clin Cancer Res 2006;12:332-339.

75. Chong ZZ, Kang JQ, Maiese K. Angiogenesis and plasticity: role of erythropoietin in vascular systems. J Hematother Stem Cell Res 2002;11:863-871.

76. Chong ZZ, Kang JQ, Maiese K. Erythropoietin: cytoprotection in vascular and neuronal cells. Curr Drug Targets Cardiovasc Haematol Disord 2003;3:141-154. 
77. Kertesz N, Wu J, Chen TH, Sucov HM, Wu H. The role of erythropoietin in regulating angiogenesis. Dev Biol 2004;276: $101-110$.

78. Martinez-Estrada OM, Rodriguez-Millan E, Gonzalez-De Vicente E, Reina M, Vilaro S, Fabre M. Erythropoietin protects the in vitro blood-brain barrier against VEGF-induced permeability. Eur J Neurosci 2003; 18:2538-2544.

79. Wang L, Zhang ZG, Zhang RL, et al. MMP 2 and MMP 9 secreted by erythropoietin-activated endothelial cells promote neural progenitor cell migration. J Neurosci 2006;26:5996-6003.

80. Shingo T, Sorokan ST, Shimazaki T, Weiss S. Erythropoietin regulates the in vitro and in vivo production of neuronal progenitors by mammalian forebrain neural stem cells. J Neurosci 2001; 21:9733-9743.

81. Kretz A, Happold CJ, Marticke JK, Isenmann S. Erythropoietin promotes regeneration of adult CNS neurons via Jak2/Stat3 and PI3K/AKT pathway activation. Mol Cell Neurosci 2005;29:569579.

82. Firestein BL, Bredt DS. Regulation of sensory neuron precursor proliferation by cyclic GMP-dependent protein kinase. J Neurochem 1998;71:1846-1853.

83. Hood J, Granger HJ. Protein kinase G mediates vascular endothelial growth factor-induced Raf-1 activation and proliferation in human endothelial cells. J Biol Chem 1998;273:23504-23508.

84. Kukreja RC, Ockaili R, Salloum F, et al. Cardioprotection with phosphodiesterase-5 inhibition: a novel preconditioning strategy. J Mol Cell Cardiol 2004;36:165-173.

85. Corbin JD, Blount MA, Weeks JL II, et al. $\left[{ }^{3} \mathrm{H}\right]$ Sildenafil binding to phosphodiesterase- 5 is specific, kinetically heterogeneous, and stimulated by cGMP. Mol Pharmacol 2003;63:1364-1372.

86. Zhang R, Wang Y, Zhang L, et al. Sildenafil (Viagra) induces neurogenesis and promotes functional recovery after stroke in rats. Stroke 2002;33:2675-2680.

87. Tahsili-Fahadan P, Yahyavi-Firouz-Abadi N, Orandi AH, Esmaeili B, Basseda Z, Dehpour AR. Rewarding properties of sildenafil citrate in mice: role of the nitric oxide-cyclic GMP pathway. Psychopharmacology (Berl) 2006;185:201-207.

88. Choi SM, Kim JE, Kang KK. Chronic treatment of DA-8159, a new phosphodiesterase type $\mathrm{V}$ inhibitor, attenuates endothelial dysfunction in stroke-prone spontaneously hypertensive rat. Life Sci 2006;78:1211-1216.

89. Zhang L, Zhang RL, Wang Y, et al. Functional recovery in aged and young rats after embolic stroke: treatment with a phosphodiesterase type 5 inhibitor. Stroke 2005;36:847-852.

90. Jin K, Sun Y, Xie L, et al. Neurogenesis and aging: FGF-2 and HB-EGF restore neurogenesis in hippocampus and subventricular zone of aged mice. Aging Cell 2003;2:175-183.

91. Zhang RL, Zhang Z, Zhang L, Wang Y, Zhang C, Chopp M. Delayed treatment with sildenafil enhances neurogenesis and improves functional recovery in aged rats after focal cerebral ischemia. J Neurosci Res 2006;83:1213-1219.

92. Wang L, Gang Zhang Z, Lan Zhang R, Chopp M. Activation of the PI3-K/Akt pathway mediates cGMP enhanced-neurogenesis in the adult progenitor cells derived from the subventricular zone. J Cereb Blood Flow Metab 2005;25:1150-1158.

93. Devan BD, Bowker JL, Duffy KB, et al. Phosphodiesterase inhibition by sildenafil citrate attenuates a maze learning impairment in rats induced by nitric oxide synthase inhibition. Psychopharmacology (Berl) 2006;183:439-445.

94. Baltrons MA, Pedraza C, Sardon T, Navarra M, Garcia A. Regulation of NO-dependent cyclic GMP formation by inflammatory agents in neural cells. Toxicol Lett 2003;139:191-198.

95. Khan M, Jatana M, Elango C, Singh Paintlia A, Singh AK, Singh I. Cerebrovascular protection by various nitric oxide donors in rats after experimental stroke. Nitric Oxide 2006. Epub 2006 Mar 6.

96. Zhang R, Wang L, Zhang L, et al. Nitric oxide enhances angiogenesis via the synthesis of vascular endothelial growth factor and cGMP after stroke in the rat. Circ Res 2003;92:308-313.

97. Zhang R, Zhang L, Zhang Z, et al. A nitric oxide donor induces neurogenesis and reduces functional deficits after stroke in rats. Ann Neurol 2001;50:602-611.

98. Chiueh CC. Neuroprotective properties of nitric oxide. Ann N Y Acad Sci 1999;890:301-311.
99. Sun BL, Zhang SM, Xia ZL, et al. L-Arginine improves cerebral blood perfusion and vasomotion of microvessels following subarachnoid hemorrhage in rats. Clin Hemorheol Microcirc 2003; 29:391-400.

100. Kimura H, Ogura T, Kurashima Y, Weisz A, Esumi H. Effects of nitric oxide donors on vascular endothelial growth factor gene induction. Biochem Biophys Res Commun 2002;296:976-982.

101. Lee PC, Kibbe MR, Schuchert MJ, et al. Nitric oxide induces angiogenesis and upregulates $\alpha_{\mathrm{v}} \beta_{3}$ integrin expression on endothelial cells. Microvasc Res 2000;60:269-280.

102. Zacharek A, Chen J, Zhang C, et al. Nitric oxide regulates angiopoietin1/Tie2 expression after stroke. Neurosci Lett 2006;404: $28-32$.

103. Kashiwagi S, Izumi Y, Gohongi T, et al. NO mediates mural cell recruitment and vessel morphogenesis in murine melanomas and tissue-engineered blood vessels. J Clin Invest 2005;115:1816-1827.

104. Chen J, Zacharek A, Li Y, et al. N-cadherin mediates nitric oxide-induced neurogenesis in young and retired breeder [rat] neurospheres. Neuroscience 2006;140:377-378.

105. Thippeswamy T, McKay JS, Morris R, Quinn J, Wong LF, Murphy D. Glial-mediated neuroprotection: evidence for the protective role of the NO-cGMP pathway via neuron-glial communication in the peripheral nervous system. GLIA 2005;49:197-210.

106. Hindley S, Juurlink BH, Gysbers JW, Middlemiss PJ, Herman MA, Rathbone MP. Nitric oxide donors enhance neurotrophininduced neurite outgrowth through a cGMP-dependent mechanism. J Neurosci Res 1997;47:427-439.

107. Ohigashi T, Brookins J, Fisher JW. Interaction of nitric oxide and cyclic guanosine $3^{\prime}, 5^{\prime}$-monophosphate in erythropoietin production. J Clin Invest 1993;92:1587-1591.

108. Imagawa S, Tarumoto $\mathrm{T}$, Suzuki N, et al. L-arginine rescues decreased erythropoietin gene expression by stimulating GATA-2 with L-NMMA. Kidney Int 2002;61:396-404.

109. Sun FY, Guo X. Molecular and cellular mechanisms of neuroprotection by vascular endothelial growth factor. J Neurosci Res 2005;79:180-184.

110. Gora-Kupilas K, Josko J. The neuroprotective function of vascular endothelial growth factor (VEGF). Folia Neuropathol 2005; 43:31-39.

111. Zhang ZG, Zhang L, Jiang Q, et al. VEGF enhances angiogenesis and promotes blood-brain barrier leakage in the ischemic brain J Clin Invest 2000;106:829-838.

112. Chae JK, Kim I, Lim ST, et al. Coadministration of angiopoietin-1 and vascular endothelial growth factor enhances collateral vascularization. Arterioscler Thromb Vasc Biol 2000;20:2573-2578.

113. Ishikawa T, Eguchi M, Wada M, et al. Establishment of a functionally active collagen-binding vascular endothelial growth factor fusion protein in situ. Arterioscler Thromb Vasc Biol 2006 Epub 2006 Jun 22.

114. Sun Y, Jin K, Xie L, et al. VEGF-induced neuroprotection, neurogenesis, and angiogenesis after focal cerebral ischemia. J Clin Invest 2003;111:1843-1851.

115. Zhang H, Vutskits L, Pepper MS, Kiss JZ. VEGF is a chemoattractant for FGF-2-stimulated neural progenitors. J Cell Biol 2003;163:1375-1384.

116. Qiu MH, Zhang R, Sun FY. Enhancement of ischemia-induced tyrosine phosphorylation of Kv1.2 by vascular endothelial growth factor via activation of phosphatidylinositol 3-kinase. J Neurochem 2003;87:1509-1517.

117. Meng H, Zhang Z, Zhang R, et al. Biphasic effects of exogenous VEGF on VEGF expression of adult neural progenitors. Neurosci Lett 2006;393:97-101.

118. Lin TN, Sun SW, Cheung WM, Li F, Chang C. Dynamic changes in cerebral blood flow and angiogenesis after transient focal cerebral ischemia in rats: evaluation with serial magnetic resonance imaging. Stroke 2002;33:2985-2991.

119. Amarenco P, Bogousslavsky J, Callahan AS, Goldstein L, Hennerici M, Sillsen H, Welch MA, Zivin J. Design and baseline characteristics of the stroke prevention by aggressive reduction in cholesterol levels (SPARCL) study. Cerebrovasc Dis $2003 ; 16: 389-395$. 